\title{
Nobel for AIDS virus discovery, finally
}

Two French virologists who discovered HIV share this year's Nobel Prize in Physiology or Medicine with a German oncovirologist who showed that human papilloma virus (HPV) causes cervical cancer. The Nobel Prize in Physics went to two Japanese researchers and a Japanese-born American for their work on symmetry breaking in subatomic physics.
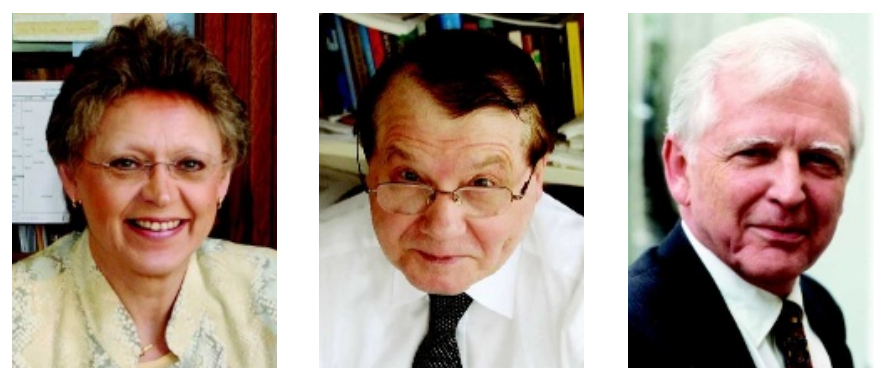

Françoise Barré-Sinoussi (left), Luc Montagnier (centre) and Harald zur Hausen share the medicine Nobel for their work on viruses.

screening agents and drugs that have helped to fight spread of the disease and dramatically increased life expectancy.

Harald zur Hausen, former director of the German Cancer Research Center (DKFZ) in Heidelberg, Germany, was honoured for going against the prevailing dogma to discover that it was not a herpes simplex virus that causes cervical cancer, but in fact HPV.

"Virologists and gynaecologists Luc Montagnier identified the human immunodeficiency virus (HIV) that causes AIDS in 1983, while working at the Pasteur Institute in Paris. They originally called it lymphadenopathy associated virus (LAV).

By awarding the prize to the French duo, the Nobel committee effectively ends years of bitter controversy arising from a counter claim for HIV's discovery by virologist Robert Gallo of the US National Institutes of Health in Bethesda, Maryland. In 1987 the French and US heads of state brokered an agreement to share the benefits of the discovery.

Many believed that the Nobel prize could not be awarded for this field of research, despite its

importance, while tempers ran high. Now, the Nobel committee has made its position clear, saying the discovery of Barré-Sinoussi and Montagnier "was accepted by the research community and resulted in an explosion of scientific breakthroughs". It then refers to Gallo's "detection of a novel ... virus from a vast number of patients with AIDS or pre-AIDS in 1984 ... [which] showed considerable similarities with LAV-1". Gallo says he is "gratified" that he was considered "equally deserving", adding that he is proud of his colleagues.

The work of the French scientists has led to the development of diagnostic tools, blood thought his idea about the papilloma virus was very strange," says Herbert Pfister, a former colleague, now at the University of Cologne in Germany. "But he carried through his theory in a determinedly logical way, not caring about the controversy he was raising."

During the 1980s, zur Hausen described first HPV-16, which occurs in around half of human cervical cancers as well as other anogenital cancers, and then HPV-18, which accounts for a further $25 \%$ of cases. His work led to the development of vaccines against HPV, which are now in widespread use and expected to slash the rates of cervical cancer,

\section{Charitable bodies hit by credit crisis}

The ongoing financial crisis in the United States and Europe is hitting major research charities and institutions.

Organizations such as the Wellcome Trust in London and Cold Spring Harbor Laboratory in New York say that their endowments have dropped for the first time in years. And some medical charities are bracing for a decline in big-dollar donations from corporations and wealthy individuals. "The events of the past few weeks are clearly going to have an impact on everybody," says Bruce Stillman, president of Cold Spring Harbor Laboratory.

Still, he and other leaders contacted by Nature are confident that sound financial management and careful planning will allow them to survive the economic crash.

The credit freeze, caused by bad loans in the housing sector in the United States and elsewhere, has brought down several leading banks and insurance companies. The time taken for US Congress to approve a \$700- billion bailout package caused markets to fall further still, and governments have been bringing out emergency measures to shore up their economies.

The markets strongly influence trends in charitable giving, according to Patrick Rooney, director of research at Indiana University's Center on Philanthropy in Indianapolis. "When the stock market was growing in double digits in the late 1990s, philanthropy was growing in double digits as well," he says. But during the US recession of 2001-03, charitable giving dropped by a few percentage points each year.

Rooney says that it is probably too early to tell how much the crisis has affected charities and endowments. Nearly onequarter of donations made by individuals and corporations are made during the autumn and early winter, and any decline in giving won't be felt until spring 2009, he says. He expects that organizations that depend mainly on endowments will fare better than charities, so long as the economic downturn is not sustained. But if the economy slides into recession, he warns, "all bets are off".

Some charities have escaped the international economic downturn unscathed. The Howard Hughes Medical Institute's \$19-billion endowment is relatively unchanged compared with August 2007, according to Thomas Cech, the institute's outgoing president. Cech says that only about one-quarter of the endowment is invested in the market and that the losses in recent months have been offset by gains earlier in the year. "We are fully confident that we can meet our upcoming commitments," he says.

But others have been directly affected by the economic turmoil. The Wellcome Trust, the world's largest medical research charity, has seen its endowment drop by $5-10 \%$ to

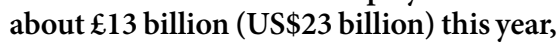
according to Mark Walport, the charity's director. 
which affects nearly 500,000 people a year and is the fifth most deadly cancer in women.

The physics prize went to Japan's Makoto Kobayashi of the High Energy Accelerator Research Organization (KEK) in Tsukuba and Toshihide Maskawa of Yukawa Institute for Theoretical Physics at Kyoto University for discovering the origin of the 'broken symmetry' that contributed to a preponderance of matter over antimatter in the Universe. They share the prize with Yoichiro Nambu of the Enrico Fermi Institute at the University of Chicago in Illinois, who discovered the mechanism by which spontaneous broken symmetry occurs in particle physics.

Symmetry breaking describes how symmetrical systems can suddenly show a preference for one direction over another. As a simple example, imagine balancing a pencil on its tip. Viewed from the top, the balanced pencil appears symmetrical, but after a time it will fall and point in a single direction.

This concept applies to many physical systems, including superconductors, but it was Nambu who extended the theory to fundamental particles, according to John Ellis, a theorist at CERN, Europe's particle-physics laboratory near Geneva, Switzerland. Physicists now think that symmetry breaking is responsible for the creation of the Higgs boson, the particle that is believed to endow all other particles with mass,
Still, Walport says that the Wellcome Trust is not anticipating any need to alter its spending. Like most charities, it gives only a small fraction of its endowment to research each year - around $£ 500$ million in 2007. That relatively low rate of spending combined with careful management ahead should allow the charity to continue normal operations. "We are weathering the storm as well as can be expected," Walport says.

Cold Spring Harbor's US\$300 million endowment is also down, says Stillman, by an estimated $5 \%$ as of 31 July. And the laboratory, which supports a broad range of basic biological science, depends on additional philanthropic and corporate support to fund its roughly $\$ 120$-million operating budget. Stillman says that the money often comes either directly from Wall Street firms or from wealthy investors. The latest fundraising efforts are on track, he says. But "obviously the situation will affect our income down the road".

Rooney says that corporations may be the first to cut back on their giving. "Corporate donations are largely driven by changes in profitability," he says.

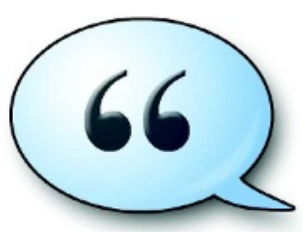

HAVE YOUR SAY Comment on any of our news stories, online. www.nature.com/news and which is a target of CERN's Large Hadron Collider.

Kobayashi and Maskawa showed how violation of symmetry could create more matter than antimatter in the Universe - a long-standing problem in particle physics. In the early 1970s, the pair showed that the interactions of quarks via a fundamental force, called 'the weak force', could cause 'CP-violation', a phenomenon by which some particles decay in a different way from their anti-matter counterparts.

"They wrote down this huge expression whose physical interpretation is the violation of symmetry between matter and antimatter," says Ken Peach, a physicist at the University of Oxford, UK. The equations also predicted a third family of quarks (the particles that make up protons and neutrons in an atom's nucleus).

The idea of a thirds family seemed "farfetched" at the time, says Ellis, but Kobayashi and Maskawa's work has since been verified by two high-energy experiments. The Belle experiment at KEK and the BaBar experiment at the Stanford Linear Accelerator Center in California both measured the decay of particles made of bottom quarks. The physicists' predictions were borne out to a high degree of accuracy. Alison Abbott and Geoff Brumfiel

To read coverage of the Nobel Prize in Chemistry, which had not been announced as Nature went to press, visit www.nature.com.

\section{Kavli invests}

\section{in institutes}

US philanthropist Fred Kavli has embarked on a second round of grants of up to $\$ 5$ million to each of the 15 research institutes that were established in his name. The grants, Kavli told Nature, are conditional on the institutes finding gifts from other donors so that they can establish endowments of $\$ 20$ million.

Kavli, who made his \$600-million fortune through real estate and selling his company - which had become a leader in supplying aeronautic and automotive sensors - says that the second round could take five years or more. "Right now the market hasn't been very kind to us," he says. "We are hedging a little on this."

Seven years ago, when Kavli established the first of the institutes, at the University of California at Santa Barbara, he developed what became a relatively strict formula:

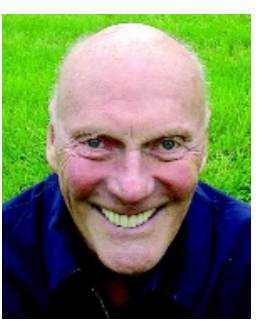

Fred Kavli is hoping to support 20 institutes. on average each university got $\$ 7.5$ million, to be supplemented and used however - for a building, for operating expenses, or for endowed professorships. Kavli got the name. for charities that depend entirely on annual donations to fund research. "Donors may raise their bar," warns Deborah Brooks, cofounder of the Michael J. Fox Foundation for Parkinson's Research in New York. Brooks says she thinks that wealthy individual donors will probably continue to give large sums but "their first instinct is to give to fewer people".

Stillman says he expects that Wall Street's woes will have a "significant" effect on research universities and charities across the state. Indeed, one important source of funding has dried up for good. Lehman Brothers, which filed for bankruptcy last month, donated roughly $\$ 7$ million to biomedical research in 2007. Most of the money went to hospitals and research centres in the New York area, with the largest amount, $\$ 6$ million, going to Weill Cornell Medical College's Lehman Brothers Lung Cancer Research Center. A spokesperson for the school declined to comment on the centre's future, saying only that it was "grateful for the many years of support by Lehman Brothers". Geoff Brumfiel
John Carlstrom, director of the Kavli
Institute for Cosmological Physics at the University of Chicago in Illinois, says that his university was not the only one that thought the gift was relatively small to be exchanged for the naming rights to an entire institute. But many assumed, apparently correctly, that more money would be coming later.

The first of the second round of gifts was completed in May to the Kavli Institute for Particle Astrophysics \& Cosmology to Stanford University in Menlo Park, California. A deal with the University of California at Santa Barbara is in the works as fundraisers find matching gifts.

Kavli, 81, says that he views the institutes, which specialize in nanoscience, neuroscience, astrophysics and theoretical physics, as his legacy - and as more important than the three $\$ 1$ million eponymous prizes that were awarded for the first time this year. But he says that he is not done yet; he eventually envisions 20 institutes. Eric Hand 